OPEN ACCESS

Edited by:

Kang Liu,

Baylor College of Medicine, USA

Reviewed by:

Lan Wang,

University of Miami, USA

Xiao-Jian Sun,

Shanghai Jiao Tong University, China

Zhao Wang,

University of Texas Southwestern

Medical Center, USA

Xunlei Kang,

University of Missouri, USA

*Correspondence: Meng Zhao

zhaom38@mail.sysu.edu.cn

${ }^{\dagger}$ These authors have contributed equally to this work.

Specialty section:

This article was submitted to Pharmacology of Anti-Cancer Drugs,

a section of the journal

Frontiers in Pharmacology

Received: 28 October 2016 Accepted: 23 December 2016

Published: 12 January 2017

Citation:

Wang J, Zheng Y and Zhao M (2017)

Exosome-Based Cancer Therapy: Implication for Targeting Cancer Stem Cells. Front. Pharmacol. 7:533 doi: 10.3389/fphar.2016.00533

\section{Exosome-Based Cancer Therapy: Implication for Targeting Cancer Stem Cells}

\author{
Jinheng Wang ${ }^{1,2+}$, Yongjiang Zheng ${ }^{1+}$ and Meng Zhao ${ }^{1,2,3 *}$ \\ ${ }^{1}$ Department of Hematology, The Third Affiliated Hospital, Zhongshan School of Medicine, Sun Yat-Sen University, \\ Guangzhou, China, ${ }^{2}$ Key Laboratory for Stem Cells and Tissue Engineering, Ministry of Education, Sun Yat-Sen University, \\ Guangzhou, China, ${ }^{3}$ Department of Pathophysiology, Zhongshan School of Medicine, Sun Yat-Sen University, Guangzhou, \\ China
}

Drug resistance, difficulty in specific targeting and self-renewal properties of cancer stem cells (CSCs) all contribute to cancer treatment failure and relapse. CSCs have been suggested as both the seeds of the primary cancer, and the roots of chemo- and radio-therapy resistance. The ability to precisely deliver drugs to target CSCs is an urgent need for cancer therapy, with nanotechnology-based drug delivery system being one of the most promising tools to achieve this in the clinic. Exosomes are cell-derived natural nanometric vesicles that are widely distributed in body fluids and involved in multiple disease processes, including tumorigenesis. Exosome-based nanometric vehicles have a number of advantages: they are non-toxic, non-immunogenic, and can be engineered to have robust delivery capacity and targeting specificity. This enables exosomes as a powerful nanocarrier to deliver anti-cancer drugs and genes for CSC targeting therapy. Here, we will introduce the current explorations of exosome-based delivery system in cancer therapy, with particular focus on several exosomal engineering approaches that have improved their efficiency and specificity for CSC targeting.

Keywords: exosomes, nanocarrier, cancer therapy, cancer stem cells, exosomal engineering

\section{INTRODUCTION}

Cancer remains one of the leading causes of death due to the late diagnosis, poor prognosis, and frequent occurrence of drug resistance and metastasis (Colak and Medema, 2014). Cancer stem cells (CSCs) are a small subpopulation of immortal cancer cells, capable of long-term self-renewal, and differentiation into heterogeneous cancer cell lineages (Bandhavkar, 2016). Although the existing of CSCs is still controversial, recently a number of studies have identified CSCs in several types of solid tumor, such as renal cancer, breast cancer, lung cancer, liver cancer, prostate cancer, melanoma, and in leukemia (Huang and Rofstad, 2016). CSCs are known as the source of primary and metastatic cancer, and the root of chemo- and radio-therapy resistance (Sales et al., 2007; Colak and Medema, 2014). Multiple mechanisms are involved in CSC drug resistance, including slow cell cycle progression, drug efflux, enhanced DNA repair efficiency, elevated anti-apoptotic capacity, and detoxification enzyme expression (Marhaba et al., 2008; Saha et al., 2012; Colak and Medema, 2014; Sotiropoulou et al., 2014; Lu et al., 2016). This combination of factors leads to the treatment failure and relapse frequently observed in cancer patients. Therefore, developing novel strategies to specifically target CSCs and overcome their drug resistance is pivotal for cancer treatment. 
Nanotechnology-based drug delivery systems are a variety of synthetic nanoparticles and biological vesicles which have biological specificity for in vivo targeting therapies. In recent years, some synthetic nanoparticles have been employed as vehicles to deliver therapeutic drugs to the bulk of the tumor, and even directly target CSCs (Lu et al., 2016). Nanoparticles also have slow drug-releasing characteristics which induce a sustained high local drug concentration around the tumor and an enhanced anti-cancer efficiency (Ahmad et al., 2016; Piktel et al., 2016). As recently reviewed by $\mathrm{Lu}$ et al. several synthetic nanoparticles, such as liposomes, niosomes, micelles, polymeric, and gold nanoparticles are able to deliver anticancer drugs to target tumor cells; this precision is made possible by their ability to use CSC specific markers such as CD44, CD90, and CD133 to target a specific population. Furthermore, the specificity of such particles is enhanced by the use of different payloads which can inhibit specific signaling pathways including Notch, Hedgehog, and transforming growth factor- $\beta$ (TGF- $\beta$ ) in CSCs (Lu et al., 2016).

Biological vesicles are naturally derived from bacteria, erythrocytes, or mammalian cells (Soltani et al., 2015). Bacterial ghosts are obtained from chemically inactivated Gram-negative bacterial cells after removal of their cytoplasmic contents. Bacterial ghosts can be used as a carrier for genes, drugs, and vaccines; however their lipopolysaccharide-caused immune responses have limited their use in vivo (Kudela et al., 2005, 2008, 2011; Mayr et al., 2005; Paukner et al., 2005). Erythrocyte ghosts are cytoplasmic-content free erythrocytes and have high biocompatibility and biodegradability. They are non-toxic and non-immunogenic with a long life span in circulation. Unfortunately their capacity for drug loading is limited, and deformations during transportation frequently cause unstable encapsulation and drug leaking, limiting their clinical use (Magnani et al., 2002; Muzykantov, 2010; Biagiotti et al., 2011; Yousefpour and Chilkoti, 2014). Exosomes, secreted from living cells, have been used as nanometric vehicles for therapeutic drug and gene delivery. They are biocompatible, non-cytotoxic, low immunogenic, simple to produce, easy to store, have a long life span, and high cargo loading capacity (Munagala et al., 2016; Srivastava et al., 2016; Wang et al., 2016b). These characteristics make exosomes a promising drug carrier for cancer treatment (Tian et al., 2013; Tang et al., 2015; Pitt et al., 2016). In this review, we provide an overview for exosome studies with a particular emphasis on current advances of exosome-mediated cancer targeting therapy.

\section{Characteristics of Exosomes}

Besides engaging in cell-cell contact and directly releasing soluble molecules through those interactions, extracellular vesicles (EVs) derived from cells also mediate the short-range and distant communications between cells (Hwang, 2013; Wang et al., 2014). EVs directly shed from the plasma membrane are heterogeneous particles with the size range of 100-1000 nm in diameter (van der Meel et al., 2014; Vader et al., 2016). Exosomes are derived from intracellular late endosomes but with a smaller size of 40$100 \mathrm{~nm}$. Exosome formation is initiated by early endosomes, followed by the formation of intraluminal vesicles (ILVs) inside the endosomes. These endosomes enclosed within mature ILVs are called multivesicular bodies (MVBs), which can either fuse with lysosomes for degradation and recycling, or release ILVs as exosomes into the extracellular matrix through fusing with plasma membrane (Théry et al., 2002; Kharaziha et al., 2012; Klumperman and Raposo, 2014).

Exosomes contain receptors on their lipid bilayer membrane and carry proteins, lipids, mRNAs, miRNAs, and small DNA fragments inside to protect them from degradation (Raimondo et al., 2011; Hwang, 2013; De Veirman et al., 2016; Wang et al., 2016a). Exosomes can be distinguished by size and specific surface markers including TSG101, Alix, Flotillin-1 CD63, CD9, among other EVs (Schorey and Bhatnagar, 2008; Soltani et al., 2015; Tang and Wong, 2015; Yu et al., 2015). Exosomes are present widely in various cell culture-conditioned media and body fluids including synovial fluid, saliva, urine, breast milk, semen, and blood. Thus, several methods have been developed to isolate exosomes from body fluids or conditioned supernatant, including differential ultracentrifugation, density gradient centrifugation, size exclusion chromatography, immunoaffinity capture, and polyethylene glycol-mediated precipitation (Tauro et al., 2012).

\section{Function of Exosomes}

As a communicator, exosomes can directly stimulate multiple types of target cells with their membrane molecules or deliver their contents into cells for direct influence (Camussi et al., 2011; Raposo and Stoorvogel, 2013). Exosomes are transferred from original cells to destination mainly through the circulating flow and thereafter localized in target area through binding their membrane molecules to target cell surface receptors for long range communication. Cancer mouse models and cancer patients have higher levels of EVs and exosomes in body fluids (Taylor and Gercel-Taylor, 2008; Ghosh et al., 2010; Benameur et al., 2013), implying the involvement of these particles in cancer progression. Indeed, accumulating evidence revealed that exosomes play a critical role in tumorigenesis. For example, exosomes derived from mesenchymal stromal cells (MSC) or fibroblasts directly facilitate cancer progression and induce drug resistance in multiple myeloma, colorectal cancer, and gastric cancer cells through delivering various miRNAs and soluble factors into tumor cells (Roccaro et al., 2013; Wang et al., 2014; Hu et al., 2015; Ji et al., 2015). Astrocyte-derived exosomes transfer the miR-17 92 cluster to suppress PTEN gene in brain tumors (Zhang et al., 2015). Malignant cells also secrete large amount of exosomes to promote endothelial cell proliferation and enhance angiogenesis, which facilities tumor progression (Umezu et al., 2014; Wang et al., 2016a). Cancer cell-derived exosomes can also induce immunosuppression in the tumor microenvironment (Chalmin et al., 2010; Wang et al., 2016a). This tumor exosome-educated microenvironment in turn facilitates tumor survival and growth. Cancer cellderived exosomes can preferentially fuse with the cells at their predicted destination to form a pre-metastatic niche for tumor metastasis (Hoshino et al., 2015). Furthermore, these cancer cell-derived exosomes can even convert normal epithelial cells to form tumors in mice (Melo et al., 2014). Acute myeloid 
leukemia cell-derived exosomes can deliver miR-155 into normal hematopoietic stem and progenitor cells (HSPCs), and suppress c-Myb expression to impair normal hematopoiesis, which in turn facilities leukemic cell growth (Hornick et al., 2016). All of these results underline the importance of exosome as a messenger for cell communication during cancer progression. Taking advantage of their natural delivery capability, exosomes have been successfully used for drug and functional RNA delivery vehicles in cancer treatment. Furthermore, an increasing number of researchers have devoted their efforts to improve the capacity, specificity, and selectivity of exosome-mediated nanodelivery in recent years.

\section{Advantages of Exosomes for Cancer Therapy}

Unlike synthetic nanoparticles, exosomes are more biocompatible and biodegradable, and thus have low toxicity and immunogenicity ( $\mathrm{Ha}$ et al., 2016). Although other cell-derived EVs are also biocompatible, they are bigger than exosomes and more heterogeneous which limited their application for drug loading and delivery. Exosomes can also be easily generated because most cell types can produce exosomes. Exosomes are stable in biological fluids and their small size enables exosomes to easily escape from lung clearance and pass through the bloodbrain barrier (Kawikova and Askenase, 2015; Li et al., 2016). Adherence and internalization of exosomes within tumor cells is 10-times higher than liposomes of a similar size, indicating a higher specificity of exosomes for cancer targeting (Smyth et al., 2014). In addition, due to enhanced permeability and retention effect, nanometric exosomes tend to accumulate in tumor tissues containing abnormally formed blood vessels than they do in normal tissues, thus exosomes can easily reach the bulk of the solid tumors to increase their drug delivery efficiency. Moreover, exosomes can be engineered with tumor-targeting proteins, peptides, or antibodies for precise drug and therapeutic nucleic acid delivery. Taken together, these characteristics make exosomes one of the best candidates for cancer targeting therapy.

\section{Exosome Modifications for Specific Targeting}

Synthetic nanoparticle-mediated delivery has low specificity because a very limited number of selective molecules can be used for cell targeting. However, natural cell-produced exosomes can recognize specific cell types via their surface receptors. For example, exosomes with Tspan 8 preferentially bind to CD11b and CD54-postive cells (Rana et al., 2012). In addition, researchers can engineer donor cells to obtain modified exosomes with particular receptors for better cell recognition. Most exosome modifications are adapted from surface display technology which presents candidate proteins or peptides on exosome membranes. To achieve this, researchers engineer donor cells to express candidate proteins or peptides fused with an exosomal membrane proteins such as lysosome-associated membrane glycoprotein 2b (Lamp2b) and tetraspanins CD63 and CD9 (Stickney et al., 2016), which will position the candidates on exosome's surface. For example, dendritic cells (DCs) were engineered to express $\alpha \mathrm{v}$ integrin-specific iRGD peptide and Lamp2b fusion protein, allowing the engineered DCs to secret exosomes with the iRDG peptide on their surface. These engineered exosomes have dramatically increased drug delivery efficiency and anti-tumor effect on $\alpha \mathrm{v}$ integrin-positive breast cancer cells in a mouse model (Tian et al., 2014). Exosomes with the neuron-specific rabies viral glycoprotein (RVG) peptide can specifically bind to the acetylcholine receptor on neuronal cells and selectively knockdown certain genes in neurons, microglia, and oligodendrocytes by specific delivery of small interfering RNA (siRNA) into those cells (Alvarez-Erviti et al., 2011). These results indicated that adapted exosomes can serve as a powerful tool for neural cancer treatment. Furthermore, glycosylated peptides on the exosome's surface are resistant to proteasome-mediated degradation in circulation, which enhances their stability and even efficiency of targeted delivery (Hung and Leonard, 2015).

A recent study has used a magnet-based method to further improve the tumor targeting specificity. Qi et al. engineered magnetic exosomes by linking superparamagnetic-conjugated transferrin to transferrin receptor-positive blood exosome surfaces, and an external magnet was put on the tumor site in vivo; this allowed the magnetic exosomes to be directed to the target tumors cells to efficiently suppress tumor growth $(\mathrm{Q}$ et al., 2016). Although the magnetic exosomes cannot directly target CSCs, the vast enrichment of exosomes loaded with potent CSC targeting drugs around solid tumors can significantly improve therapeutic efficiency and limit their side-effects by restricting drugs on tumor site. The anti-tumor specificity can be further improved by presenting specific anti-tumor antibodies on exosome surface. In one study, an engineered anti-epidermal growth factor receptor (EGFR) nanobody and exosome anchor signal peptide glycosylphosphatidylinositol (GPI) fusion protein were transfected to donor cells to generate nanobody-presenting exosomes. These exosomes were capable of directly targeted EGFR-positive tumor cells (Kooijmans et al., 2016).

Protecting drug-loaded exosomes from liver clearance is critical for their cancer treatment applications. Researchers blocked scavenger receptor class A family (SR-A), a monocyte/macrophage uptake receptor for exosomes, which dramatically reduced exosome liver clearance and enhanced their accumulation in tumor (Watson et al., 2016). Another approach involving exosome-liposome hybridization was also used to increase their specificity and stability (Sato et al., 2016). Nakase and Futaki utilized cationic lipids as "glue" to display $\mathrm{pH}$-sensitive fusogenic peptides on exosome surfaces which enhanced their cell membrane binding and cell uptake efficiency of exosomes. After endocytosis, these peptides facilitated exosome and endosome fusion, which increased the releasing of exosomal cargos in cytoplasm (Nakase and Futaki, 2015).

Taken together, the success of these exosomal adapting methods, as summarized in Figure 1, provide an effective CSC treatment prospect and the combination of them will further improve the outcome of exosome-mediated CSC targeting. 


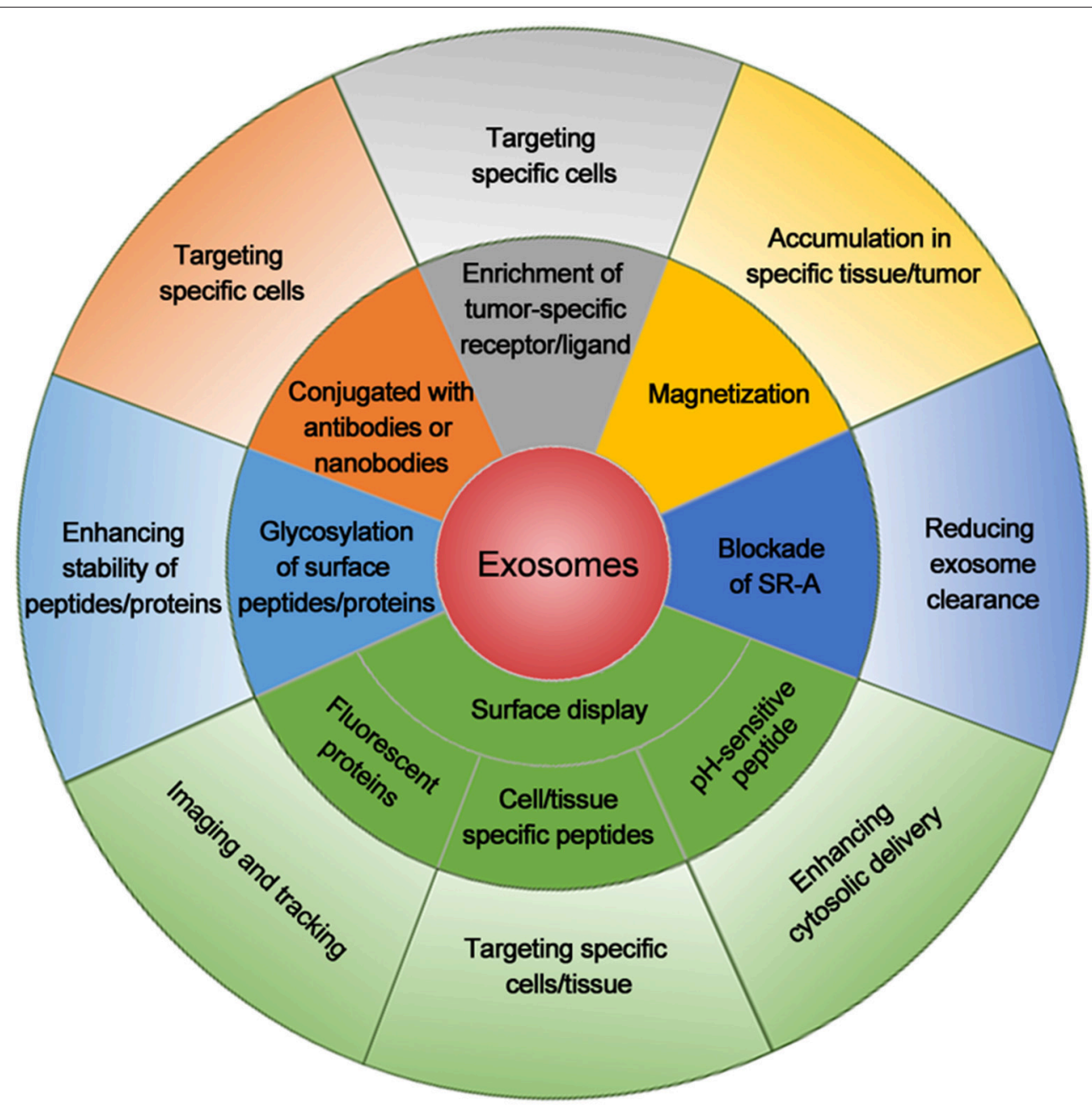

FIGURE 1 | Summary of exosomal modifications to enhance their cancer cell targeting efficiency. Exosomes with cell/tissue-specific peptides, tumor-specific receptors/ligands, or antibodies/nanobodies for tumor markers increase their specificity for cancer cell targeting. Exosomes displaying fluorescent protein or chemical on the surface are used for imaging or tracking. Magnetization of exosomes elevates their accumulation around the tumor. Blockade of scavenger receptor class A family (SR-A) reduces the clearance of exosomes by liver and increases exosome concentration in circulation and tumor. Exosome linked with $\mathrm{pH}$-sensitive peptide enhances the cytosolic delivery. Glycosylation of peptides/proteins on exosome surface increases the stability of exosomes and thus enhances their delivery efficiency. The combination of these methods will further enhance the delivery efficacy and specificity for cancer cell targeting.

\section{Exosome Cargo Loading for Cancer Therapy}

As a delivery system, exosomes are widely used as vehicles for various tumor therapeutic cargos. The lipid bilayer membrane of exosomes forms a natural protective shelter and a sustained release capsule for various anti-cancer drugs. Various anticancer drugs and cancer gene suppressors, including functional RNAs, have been used for exosome based tumor treatment (Seow and Wood, 2009; Camussi and Quesenberry, 2013). To get the best tumor treatment effect, high efficacy exosome loading methods are critical. Small membrane-permeable agent loading can be achieved by incubating agents with exosomes (Hood, 2016). However, to load membrane-impermeable drugs, miRNAs, siRNAs, and small DNAs, electroporation is required to create pores on exosome lipid bilayer membrane to allow them to be encased within exosomes (Wahlgren et al., 2012; Hood et al., 2014; Momen-Heravi et al., 2014). Unfortunately, even though commercial membrane-permeable reagents such as liposomes have been used for assisting RNA and DNA fragment loading into exosomes, their efficiency did not satisfy most of the researchers (Wahlgren et al., 2012; Shtam et al., 2013). Pre-overexpression of candidate RNAs or proteins in donor cells is still considered as the best way to generate candidate protein- and RNA-loaded exosomes (Munoz et al., 2013).

\section{Anticancer Agents}

The best exosome cancer therapy is to have chemotherapeutic drug-loaded exosomes specifically targeting CSCs in vivo. Accumulating evidence has shown that exosome-mediated chemotherapeutic delivery has much improved anti-tumor 
effects when compared to free drugs in animal tumor models. For example, doxorubicin is a common chemotherapeutic drug to treat hematological malignancies and many types of solid tumors and sarcomas. Doxorubicin is fluorescent and easily tracked, therefore it has been well studied in exosome-mediated cancer therapy. In a colon adenocarcinoma mouse model, exosome-delivered doxorubicin shrank tumor size much more efficiently than did free or liposome-delivered doxorubicin (Jang et al., 2013). Furthermore, using $\alpha v$ integrin-specific iRGD peptide presenting exosomes to deliver doxorubicin dramatically enhanced the anti-tumor effect in $\alpha \mathrm{v}$ integrin-positive breast cancer cells in animals compared to free drug administration (Tian et al., 2014). Notably, exosome-mediated doxorubicin delivery has dramatically reduced its cardiotoxicity, which is considered to be the major side effect of doxorubicin in clinical applications (Toffoli et al., 2015). This is due to the exosomemediated restriction of doxorubicin from crossing through myocardial endothelial cells (Hadla et al., 2016). Due to the advantages of this delivery system, higher concentrations of doxorubicin can be used to treat breast and ovarian tumors while reducing off-target effects (Hadla et al., 2016). Overall, these studies suggest that exosome-mediated doxorubicin delivery has great prospects for clinical application.

Paclitaxel is another widely used antimitotic chemotherapeutic drug for various tumor therapy (Liu et al., 2015; Bakrania et al., 2016). Paclitaxel can be loaded into exosomes by sonication, and these loaded exosomes have 50 times more cytotoxicity than free paclitaxel for drug resistant cancer cells in vitro. They can also dramatically block murine Lewis lung carcinoma pulmonary metastases and reduce tumor size in the mouse model (Kim et al., 2016). This indicates that exosome-encapsulated paclitaxel can directly target drug resistant CSCs. Moreover, prostate cancer cell-derived exosomes loaded with paclitaxel also have enhanced cytotoxicity to autologous cancer cells (Saari et al., 2015). Interestingly, drugpretreated donor cells can also produce drug-loaded exosomes. For example, exosomes derived from paclitaxel-treated MSCs exhibited a strong inhibitory effect on human pancreatic adenocarcinoma (Pascucci et al., 2014).

Withaferin A, a potent inhibitor of angiogenesis and cancer growth, has also been tested in exosome-mediated delivery therapy. Either intraperitoneal or oral administration of exosomes-loaded withaferin A showed a much stronger antitumor effect compared to free drugs in human lung cancer xenograft mouse model (Munagala et al., 2016). Exosomes loaded with celastrol, a triterpenoid derived from plants (Chang et al., 2003), also showed stronger anti-tumor effect compared to free celastrol in human lung cancer cell xenograft model (Aqil et al., 2016). Some hydrophobic anti-tumor drugs such as curcumin, can be easily incorporated into exosome surfaces through the lipid bilayer membrane binding (Sun et al., 2010; Hood, 2016), which qualifies them as potential candidates for exosome-mediated drug delivery.

\section{Peptides and Proteins}

Besides anti-cancer therapeutic drugs, exosomes can also deliver various tumor antigens (Cho et al., 2005), apoptosis-inducing proteins (Hall et al., 2016), nanobodies (Kooijmans et al., 2016), deficient or mutant anti-apoptosis proteins (Aspe et al., 2014), tumor and tissue-specific peptides (Hung and Leonard, 2015), proteasomes (Lai et al., 2012), transferrins, and lactoferrins (Malhotra et al., 2016) into cancer cells for targeting therapy.

DCs are widely used for $\mathrm{T}$ cell-mediated immunotherapy by presenting tumor antigens to naive $\mathrm{T}$ cells, however this strategy is limited by the short life span of DCs after activation (Hermans et al., 2000). Nevertheless, researchers found that exosomes derived from peptide-pulsed DCs, can present antigens to $\mathrm{T}$ cells to induce their immune response. These DC-derived exosomes contain MHC-peptide complexes and co-stimulatory molecules on their membrane, which enable them to prolong antigen presentation and boost immunization in mice compared to antigen-presenting DCs (Luketic et al., 2007). Furthermore, exosomes isolated from two MHC type-distinct mouse cell lines expressing tumor antigen human mucin 1 (hMUC1), induced an effective immune response and suppressed hMUC1-expressing tumor cell growth in mice (Cho et al., 2005). Exosomes obtained from malignant mesothelioma cells were found to contain tumor antigens; administration of these exosomes can improve the overall survival of mesothelioma-bearing mice by activating antitumor immune responses (Mahaweni et al., 2013).

Survivin, an anti-apoptotic protein, plays important roles in multiple cancer cells to suppress apoptosis activation. Inactive mutation survivin-T34A, impair its pro-survival activity and induce caspase activation and apoptosis in cancer cells (Aspe and Wall, 2010). Survivin-T34A-loaded exosomes can induce apoptosis in various pancreatic adenocarcinoma cell lines, and enhance their sensitivity to gemcitabine (Aspe et al., 2014). Natural cell-derived exosomes also contain multiple activated and functional proteins which could also facilitate the effect of cancer therapy. One study detected high levels of all seven $\alpha$ and seven $\beta$ chains of the 20 s proteasome and three $\beta$ subunits of the immunoproteasome in MSC-derived exosomes (Lai et al., 2012), implicating a therapeutic potential to target cancer cells by using exosome-delivered proteasomes.

\section{RNAs}

Abundant miRNAs are frequently detected in exosomes isolated from either cell culture medium or bodily fluids ( $\mathrm{Yu}$ et al., 2015). Most of these miRNAs are functionally involved in exosome-mediated cell-cell communication, and a subset of them exhibited anti-cancer properties. For example, miR146b-enriched exosomes efficiently transfer miR-146b into glioma cells, inhibiting their proliferation, and reducing glioma xenograft growth in rats (Katakowski et al., 2013). EGFR-specific binding peptide GE11 can guide Let-7a-containing exosomes to EGFR-positive cancer cells, which dramatically inhibited EGFR-positive human breast cancer cell growth in a xenograft mouse model (Ohno et al., 2013). Moreover, exogenous miRNA143-loaded exosomes significantly reduced osteosarcoma cell migration (Shimbo et al., 2014).

MiR-122-transfected MSCs derived from adipose tissue can produce miR-122 loaded exosomes. These miRNA-loaded exosomes can deliver miR-122 into hepatocellular carcinoma cells to increase their sensitivity to chemotherapeutic agents 
through altering genes such as cyclin G1, a disintegrin, metalloproteinase domain-containing protein 10 (ADAM10), and insulin-like growth factor receptor 1 . Furthermore, miR-122loaded exosomes dramatically reduced human hepatocellular carcinoma growth in xenograft mice (Lou et al., 2015). MiR-134-enriched exosomes can reduce breast cancer cell migration, invasion, and enhance their chemosensitivity through suppressing transcription $5 \mathrm{~B}$, heat shock protein 90, and $\mathrm{Bcl}-$ 2 (O'Brien et al., 2015). MSC-derived exosomes loaded with anti-miR-9 are able to reverse the expression of multidrug transporters in drug resistant glioblastoma multiforme cells, leading to an enhanced sensitivity to temozolomide treatment (Munoz et al., 2013). In contrast, exosomes derived from docetaxel- or adriamycin-resistant breast cancer cells contain distinct miRNAs which can decrease the drug sensitivity in targeted tumor cells (Chen et al., 2014; Mao et al., 2016). In this case, drug resistance can be transferred from CSCs to other tumor cells. This solidifies the importance of blocking CSC-exosome transfer as an important aspect of cancer therapy.

Using exosomes to silence genes in tumor cells by loading them with siRNAs has been explored in recent years (AlvarezErviti et al., 2011; El-Andaloussi et al., 2012). For example, delivery of siRNA against RAD51 via exosomes dramatically inhibited the proliferation of human breast cancer cells and caused their death in vitro (Shtam et al., 2013). Exosomemediated transfer of siRNA against c-Myc can efficiently silence c-Myc and activate the pro-apoptotic protein caspase-3 in mouse lymphoma cells (Lunavat et al., 2016). Exosomes can also deliver PLK-1 siRNA into bladder cancer cells to silence PLK-1, reducing their proliferation (Greco et al., 2016).

Although exosome mediated anti-cancer effects were observed in various tumor models (Table 1), more in vivo and

\begin{tabular}{|c|c|c|c|c|c|c|}
\hline Cargo & Origin of exosomes & Target cancer type & Loading method & $\begin{array}{l}\text { Administration } \\
\text { route }\end{array}$ & Outcome & References \\
\hline Doxorubicin & Monocyte or macrophage & Colon adenocarcinoma & Incubation & i.v. & Inhibition of tumor growth & Jang et al., 2013 \\
\hline Doxorubicin & Breast cancer cell & $\begin{array}{l}\text { Breast and ovarian } \\
\text { tumor }\end{array}$ & Electroporation & i.p. & Inhibition of tumor growth & Hadla et al., 2016 \\
\hline Doxorubicin & $\begin{array}{l}\text { Immature DC expressing } \\
\text { iRGD }\end{array}$ & $\begin{array}{l}\alpha \vee \text { integrin-positive } \\
\text { breast cancer }\end{array}$ & Electroporation & i.v. & Inhibition of tumor growth & Tian et al., 2014 \\
\hline Doxorubicin & Blood & Hepatoma & Incubation & i.v. & Inhibition of tumor growth & Qi et al., 2016 \\
\hline Paclitaxel & MSC & $\begin{array}{l}\text { Pancreatic } \\
\text { adenocarcinoma }\end{array}$ & Incubation & $\mathrm{N} / \mathrm{A}$ & Inhibition of proliferation & Pascucci et al., 2014 \\
\hline Paclitaxel & Prostate cancer cell & Prostate cancer & Incubation & $\mathrm{N} / \mathrm{A}$ & Increased cytotoxicity & Saari et al., 2015 \\
\hline Paclitaxel & Macrophage & $\begin{array}{l}\text { Drug resistant cells, } \\
\text { lung carcinoma }\end{array}$ & $\begin{array}{l}\text { Incubation, sonication, } \\
\text { electroporation }\end{array}$ & i.n. & $\begin{array}{l}\text { Overcome drug resistance; } \\
\text { inhibition of tumor growth }\end{array}$ & Kim et al., 2016 \\
\hline Withaferin A & Bovine milk & Breast and lung cancer & Incubation & i.p. & Inhibition of tumor growth & Munagala et al., 2016 \\
\hline Celastrol & Bovine milk & Lung cancer & Incubation & i.g. & Inhibition of tumor growth & Aqil et al., 2016 \\
\hline hMUC1 & $\begin{array}{l}\text { hMUC1-expressing } \\
\text { carcinoma cell }\end{array}$ & $\begin{array}{l}\text { hMUC1-expressing } \\
\text { carcinoma }\end{array}$ & Pre-overexpression & i.d. & Inhibition of tumor growth & Cho et al., 2005 \\
\hline $\begin{array}{l}\text { Survivin-T34A } \\
\text { mutant }\end{array}$ & Melanoma cell & $\begin{array}{l}\text { Pancreatic } \\
\text { adenocarcinoma }\end{array}$ & Pre-overexpression & N/A & $\begin{array}{l}\text { Induction of apoptosis, } \\
\text { enhanced chemosensitivity }\end{array}$ & Aspe et al., 2014 \\
\hline miR-146b & MSC & Glioma & Pre-overexpression & i.t. & Inhibition of tumor growth & Katakowski et al., 2013 \\
\hline let-7a & $\begin{array}{l}\text { HEK293 cell expressing } \\
\text { GE11 }\end{array}$ & $\begin{array}{l}\text { EGFR-expressing } \\
\text { breast cancer }\end{array}$ & Pre-transfection & i.v. & Inhibition of tumor growth & Ohno et al., 2013 \\
\hline $\operatorname{miR}-143$ & MSC & Osteosarcoma & Pre-transfection & N/A & Inhibition of migration & Shimbo et al., 2014 \\
\hline miR-122 & MSC & $\begin{array}{l}\text { Hepatocellular } \\
\text { carcinoma }\end{array}$ & Pre-overexpression & i.t. & $\begin{array}{l}\text { Enhanced drug sensitivity, } \\
\text { inhibition of tumor growth }\end{array}$ & Lou et al., 2015 \\
\hline miR-134 & Breast cancer cell & $\begin{array}{l}\text { Triple-negative breast } \\
\text { cancer }\end{array}$ & Pre-transfection & N/A & $\begin{array}{l}\text { Reduced migration and } \\
\text { invasion; enhanced } \\
\text { chemosensitivity }\end{array}$ & O'Brien et al., 2015 \\
\hline Anti-miR-9 & MSC & $\begin{array}{l}\text { Drug resistant } \\
\text { glioblastoma } \\
\text { multiforme }\end{array}$ & Pre-overexpression & $\mathrm{N} / \mathrm{A}$ & Enhanced chemosensitivity & Munoz et al., 2013 \\
\hline RAD51 siRNA & Breast cancer cell & Breast cancer & $\begin{array}{l}\text { Transfection, } \\
\text { electroporation }\end{array}$ & $\mathrm{N} / \mathrm{A}$ & $\begin{array}{l}\text { Inhibition of proliferation; } \\
\text { induction of apoptosis }\end{array}$ & Shtam et al., 2013 \\
\hline c-Myc siRNA & Monocytic cell & Lymphoma & Electroporation & $\mathrm{N} / \mathrm{A}$ & Induction of apoptosis & Lunavat et al., 2016 \\
\hline PLK-1 siRNA & HEK293 cell or MSC & Bladder cancer & Electroporation & N/A & $\begin{array}{l}\text { Inhibition of proliferation; } \\
\text { induction of apoptosis }\end{array}$ & Greco et al., 2016 \\
\hline
\end{tabular}

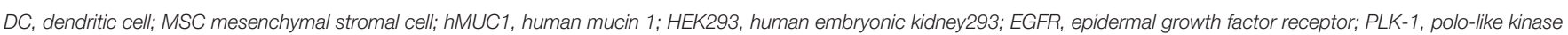
1; i.v., intravenous; i.p., intraperitoneal; i.n., intranasal; i.g., intragastrical; i.d., intradermal; i.t., intratumoral; N/A, not applicable. 
clinical evidence for different kinds of tumors are still needed. Therefore, developing more specific CSC targeting exosomes will be a promising cancer therapy strategy in the future.

\section{Opportunities for Exosome-Mediated CSC Targeting Delivery}

As described above, exosome-mediated cancer therapy has been widely studied and proved to have great potential for CSC targeting. Using the identified CSC features, we can improve current exosome engineering techniques to allow more precise targeting (Figure 2). The cell surface marker CD44 is highly expressed in high tumorigenic and metastatic hepatocellular CSCs, and Anti-CD44 antibody-coated liposomes can deliver doxorubicin directly to CSCs positive for this marker (Arabi et al., 2015). Interestingly, the anti-CD44 antibody itself can induce the apoptosis of $\mathrm{CD}^{+} 0^{+}$hepatocellular carcinoma stem cells (Yang et al., 2008). Conceivably, an anti-CD44 antibodycoated exosome could directly induce CSC death, along with their drug delivery role. Therefore, other CSC markers like CD133, CD24, epithelial cell adhesion molecule (EpCAM), and CD200, can also be used as targeting candidates to improve the exosome-mediated CSC targeting efficiency. Since CSC cell surface markers can vary from tumor to tumor, in the future multiple-antibody coated exosomes will need to be engineered to improve their CSC targeting efficiency and to reduce the side effect on normal cells; this because normal cells may present one CSC cell surface marker, but not several of them simultaneously. In addition to targeting cell surface markers, exosomes can also target CSC specific signal pathways. For example, Wnt, Notch, Hippo, Hedgehog, NF- $\kappa$ B, and TGF- $\beta$ pathways are crucial to maintain the CSC capacities such as self-renewal, differentiation, tumor initiation, and drug resistance (Dandawate et al., 2016; Huang and Rofstad, 2016; Rinkenbaugh and Baldwin, 2016). Using exosomes loaded with inhibitors, miRNAs, or siRNAs to target these pathways can be considered an alternative way to achieve CSC targeting.

\section{Clinical Trials of Exosomes in Cancer Therapy}

Since many promising results have been achieved in vitro and in animal models, using exosomes for CSC targeting is considered to be one of the most hopeful approaches for cancer treatment. Notably, some clinical trials have already made important achievements (Table 2). As showed in a phase I trial, metastatic melanoma patients were intradermally and subcutaneously given exosomes obtained from autologous DCs and loaded with the MAGE tumor antigens for 4 weeks. Although no significant outcome has been observed yet, the safety and feasibility of exosome administration have been confirmed in these patients (Escudier et al., 2005). Another phase I trial showed that the

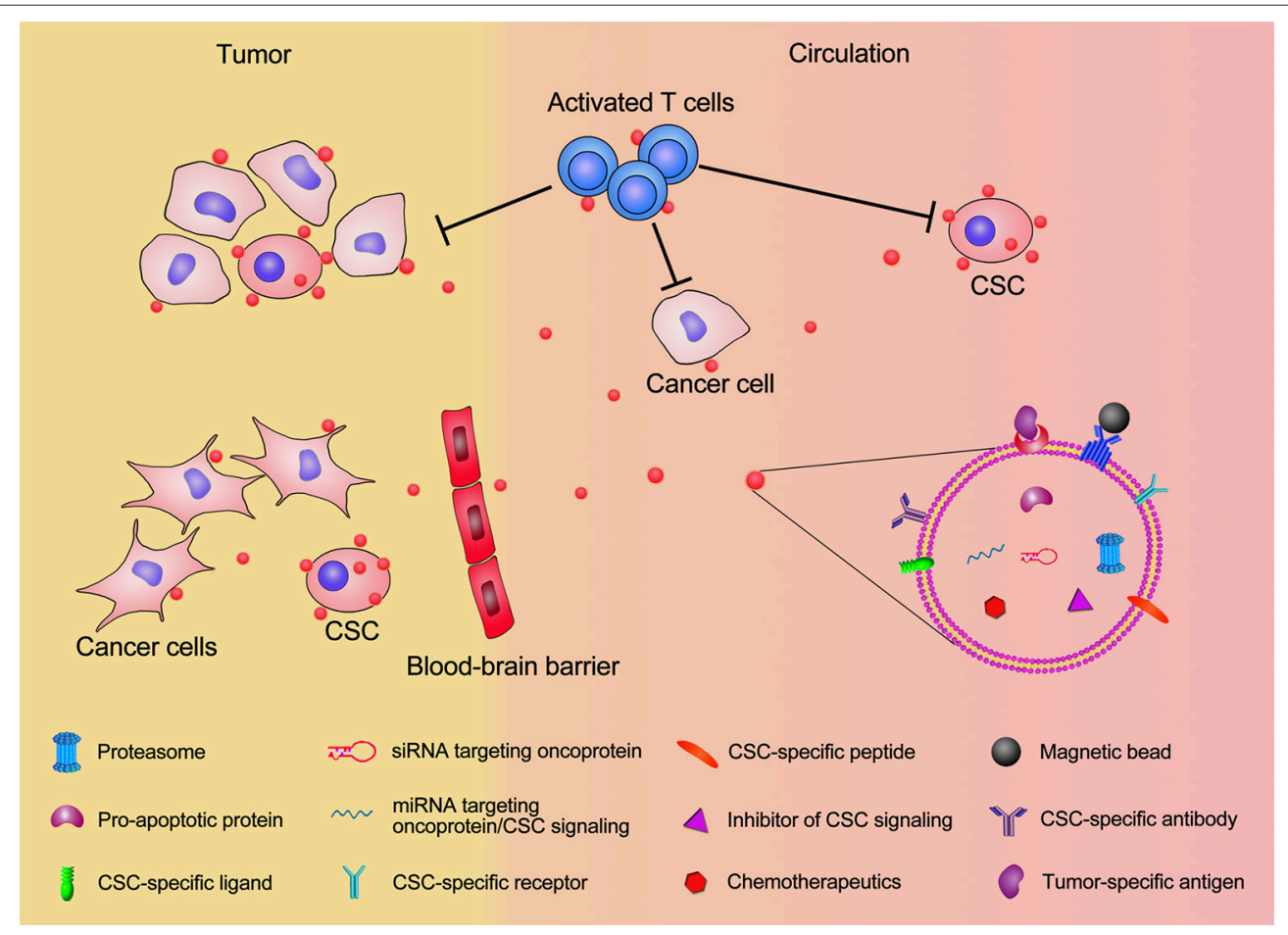

FIGURE 2 | Schematic illustration of exosomal modification and cargo loading for CSC targeting. Exosomes displaying CSC-specific peptides, magnetic beads, CSC-specific receptor/ligand, and antibodies for CSC surface maker will significantly enhance the accumulation of exosomes in tumor and increase their CSC targeting specificity. The therapeutic exosome cargos, including chemotherapeutics, inhibitors of CSC signaling, siRNA/miRNA targeting oncoprotien and CSC signaling, pro-apoptotic proteins, and proteasome will elevate the efficiency of killing CSCs. Exosomes present CSC-specific antigens to T cells and activate T cells for anti-CSC immunization. Modified exosome carrying therapeutic cargos can pass through the blood-brain barrier and facilitate CSC targeting in brain tumor. 
TABLE 2 | Human clinical trials of exosomes in cancer therapy.

\begin{tabular}{|c|c|c|c|c|c|}
\hline Cargo & Origin of exosomes & Cancer type & Phase & Results & References \\
\hline $\begin{array}{l}\text { Tumor antigenic } \\
\text { peptides }\end{array}$ & $\begin{array}{l}\text { Dendritic cells pulsed with } \\
\text { antigenic peptides }\end{array}$ & Melanoma & I & Proof of Feasibility and Safety; toxicity < Grade II & Escudier et al., 2005 \\
\hline $\begin{array}{l}\text { Tumor antigenic } \\
\text { peptides }\end{array}$ & $\begin{array}{l}\text { Dendritic cells pulsed with } \\
\text { antigenic peptides }\end{array}$ & Non-small lung cancer & I & $\begin{array}{l}\text { Proof of feasibility and Safety; toxicity < Grade I-II, } \\
\text { 9/13 completed therapy }\end{array}$ & Morse et al., 2005 \\
\hline \multirow[t]{2}{*}{$\begin{array}{l}\text { Tumor antigenic } \\
\text { peptides }\end{array}$} & $\begin{array}{l}\text { IFN- } \gamma \text {-matured dendritic cells } \\
\text { pulsed with antigenic peptides }\end{array}$ & $\begin{array}{l}\text { Advanced non-small } \\
\text { cell lung cancer }\end{array}$ & $\|$ & $\begin{array}{l}32 \% \text { of participants experienced stabilization for } \\
\text { more than } 4 \text { months; boosted NK cell-mediated } \\
\text { anti-tumor immunity }\end{array}$ & Besse et al., 2016 \\
\hline & Autologous ascites & Colon Cancer & I & Proof of feasibility and Safety; Toxicity < Grade I-II & Dai et al., 2008 \\
\hline Curcumin & Plant & Colon Cancer & I & Ongoing & NCT01294072 \\
\hline
\end{tabular}

immune response was activated and disease progression was slowed in a small number of exosome-treated non-small cell lung cancer patients (Morse et al., 2005). Evidence showed that exosomes with interferon- $\gamma($ IFN- $\gamma)$ treatment have enhanced immune activation and tumor suppression effects (Viaud et al., 2011). Based on these phase I and preclinical results, a phase II trial was performed which showed that IFN- $\gamma$-DC-derived exosomes were capable of boosting NK cell-mediated anti-tumor immunity in advanced non-small cell lung cancer patients. Thirty two percent of participants experienced stabilization for more than 4 months, although the primary endpoint has not yet been reached (Besse et al., 2016). An ascite-derived exosomes combined with GM-CSF treatment was revealed in a phase I clinical trial for colorectal cancer, showing the induction of beneficial tumor-specific antitumor cytotoxic T lymphocyte response (Dai et al., 2008). Another ongoing phase I clinical trial is trying to determine the ability of plant exosomes to deliver curcumin to colon tumor (NCT01294072, http://www. clinicaltrials.gov).

Overall, multiple clinical trials are ongoing. In the future, standardization of the exosome isolation, storage, cargo loading, quality control, and efficacy evaluation procedures will be necessary for clinical trial and treatment.

\section{Perspective}

Exosomes, as a natural nanocarrier, have great potential as a cancer therapy; however, more work is still needed, especially for in vivo studies and clinical trials. Exosomes derived from cancer

\section{REFERENCES}

Ahmad, J., Akhter, S., Khan, M. A., Wahajuddin, M., Greig, N. H., Kamal, M. A., et al. (2016). Engineered nanoparticles against MDR in Cancer: the state of the art and its prospective. Curr. Pharm. Des. 22, 4360-4373. doi: $10.2174 / 1381612822666160617112111$

Alvarez-Erviti, L., Seow, Y., Yin, H., Betts, C., Lakhal, S., and Wood, M. J. (2011). Delivery of siRNA to the mouse brain by systemic injection of targeted exosomes. Nat. Biotechnol. 29, 341-345. doi: 10.1038/nbt.1807

Aqil, F., Kausar, H., Agrawal, A. K., Jeyabalan, J., Kyakulaga, A. H., Munagala, R., et al. (2016). Exosomal formulation enhances therapeutic response of celastrol against lung cancer. Exp. Mol. Pathol. 101, 12-21. doi: 10.1016/j.yexmp.2016.05.013

Arabi, L., Badiee, A., Mosaffa, F., and Jaafari, M. R. (2015). Targeting CD44 expressing cancer cells with anti-CD44 monoclonal antibody cells carry functional cargos which directly or indirectly facilitate tumor cell growth (Wang et al., 2014, 2015, 2016a). Therefore, how to identify and remove those tumor supporting components from exosomes is critical for exosome-mediated cancer therapy, and efforts to improve the cargo loading efficiency of exosomes should be a focus going forward. Currently, electroporation is still the best way for loading siRNAs, miRNAs, and small DNA fragments into exosomes, unfortunately this process often induces their aggregation and degradation (Kooijmans et al., 2013). An improved method for sensitive cargo loading, such as siRNA and mRNA, is urgently needed. Using functional exosomes to facilitate immunotherapy is a promising therapy for cancer treatment, since exosomes are more stable than activated antigen presenting cells and can be easily engineered. These features result in exosome-based delivery systems being one of the best approaches for CSC targeting therapy.

\section{AUTHOR CONTRIBUTIONS}

JW and YZ wrote the manuscript and prepared figures. MZ provided critical comments and revised the manuscript.

\section{ACKNOWLEDGMENTS}

MZ is supported by Zhongshan School of Medicine, Sun-Yat Sun University and the Thousand Talents Plan in China. We appreciate Darrick Hansen for English editing.

improves cellular uptake and antitumor efficacy of liposomal doxorubicin. J. Control Release 220(Pt A), 275-286. doi: 10.1016/j.jconrel.2015. 10.044

Aspe, J. R., Diaz Osterman, C. J., Jutzy, J. M., Deshields, S., Whang, S., and Wall, N. R. (2014). Enhancement of Gemcitabine sensitivity in pancreatic adenocarcinoma by novel exosome-mediated delivery of the Survivin-T34A mutant. J. Extracell. Vesicles 3:23244. doi: 10.3402/jev.v3. 23244

Aspe, J. R., and Wall, N. R. (2010). Survivin-T34A: molecular mechanism and therapeutic potential. Onco Targets Ther. 3, 247-254. doi: 10.2147/OTT.S15293

Bakrania, A. K., Variya, B. C., and Patel, S. S. (2016). Novel targets for paclitaxel nano formulations: hopes and hypes in triple negative breast cancer. Pharmacol. Res. 111, 577-591. doi: 10.1016/j.phrs.2016.07.023

Bandhavkar, S. (2016). Cancer stem cells: a metastasizing menace! Cancer Med. 5, 649-655. doi: 10.1002/cam4.629 
Benameur, T., Chappard, D., Fioleau, E., Andriantsitohaina, R., Martinez, M. C., Clere, N., et al. (2013). Plasma cells release membrane microparticles in a mouse model of multiple myeloma. Micron 54-55, 75-81. doi: 10.1016/ j.micron.2013.08.010

Besse, B., Charrier, M., Lapierre, V., Dansin, E., Lantz, O., Planchard, D., et al. (2016). Dendritic cell-derived exosomes as maintenance immunotherapy after first line chemotherapy in NSCLC. Oncoimmunology 5:e1071008. doi: 10.1080/2162402X.2015.1071008

Biagiotti, S., Paoletti, M. F., Fraternale, A., Rossi, L., and Magnani, M. (2011). Drug delivery by red blood cells. IUBMB Life 63, 621-631. doi: 10.1002/iub.478

Camussi, G., Deregibus, M. C., Bruno, S., Grange, C., Fonsato, V., and Tetta, C. (2011). Exosome/microvesicle-mediated epigenetic reprogramming of cells. Am. J. Cancer Res. 1, 98-110.

Camussi, G., and Quesenberry, P. J. (2013). Perspectives on the potential therapeutic uses of vesicles. Exosomes Microvesicles 1, 1-14. doi: 10.5772/57393

Chalmin, F., Ladoire, S., Mignot, G., Vincent, J., Bruchard, M., RemyMartin, J. P., et al. (2010). Membrane-associated Hsp72 from tumor-derived exosomes mediates STAT3-dependent immunosuppressive function of mouse and human myeloid-derived suppressor cells. J. Clin. Invest. 120, 457-471. doi: 10.1172/JCI40483

Chang, F. R., Hayashi, K., Chen, I. H., Liaw, C. C., Bastow, K. F., Nakanishi, Y., et al. (2003). Antitumor agents. 228. five new agarofurans, Reissantins A-E, and cytotoxic principles from Reissantia buchananii. J. Nat. Prod. 66, 1416-1420. doi: $10.1021 / \mathrm{np} 030241 \mathrm{v}$

Chen, W. X., Cai, Y. Q., Lv, M. M., Chen, L., Zhong, S. L., Ma, T. F., et al. (2014). Exosomes from docetaxel-resistant breast cancer cells alter chemosensitivity by delivering microRNAs. Tumour Biol. 35, 9649-9659. doi: 10.1007/s13277-014-2242-0

Cho, J. A., Yeo, D. J., Son, H. Y., Kim, H. W., Jung, D. S., Ko, J. K., et al. (2005). Exosomes: a new delivery system for tumor antigens in cancer immunotherapy. Int. J. Cancer 114, 613-622. doi: 10.1002/ijc.20757

Colak, S., and Medema, J. P. (2014). Cancer stem cells-important players in tumor therapy resistance. FEBS J. 281, 4779-4791. doi: 10.1111/febs.13023

Dai, S., Wei, D., Wu, Z., Zhou, X., Wei, X., Huang, H., et al. (2008). Phase I clinical trial of autologous ascites-derived exosomes combined with GM-CSF for colorectal cancer. Mol. Ther. 16, 782-790. doi: 10.1038/mt.2008.1

Dandawate, P. R., Subramaniam, D., Jensen, R. A., and Anant, S. (2016). Targeting cancer stem cells and signaling pathways by phytochemicals: novel approach for breast cancer therapy. Semin. Cancer Biol. 40-41, 192-208. doi: 10.1016/j.semcancer.2016.09.001

De Veirman, K., Wang, J., Xu, S., Leleu, X., Himpe, E., Maes, K., et al. (2016). Induction of miR-146a by multiple myeloma cells in mesenchymal stromal cells stimulates their pro-tumoral activity. Cancer Lett. 377, 17-24. doi: 10.1016/j.canlet.2016.04.024

El-Andaloussi, S., Lee, Y., Lakhal-Littleton, S., Li, J., Seow, Y., Gardiner, C., et al. (2012). Exosome-mediated delivery of siRNA in vitro and in vivo. Nat. Protoc. 7, 2112-2126. doi: 10.1038/nprot.2012.131

Escudier, B., Dorval, T., Chaput, N., Andre, F., Caby, M. P., Novault, S., et al. (2005). Vaccination of metastatic melanoma patients with autologous dendritic cell (DC) derived-exosomes: results of thefirst phase I clinical trial. J. Transl. Med. 3:10. doi: 10.1186/1479-5876-3-10

Ghosh, A. K., Secreto, C. R., Knox, T. R., Ding, W., Mukhopadhyay, D., and Kay, N. E. (2010). Circulating microvesicles in B-cell chronic lymphocytic leukemia can stimulate marrow stromal cells: implications for disease progression. Blood 115, 1755-1764. doi: 10.1182/blood-2009-09-242719

Greco, K. A., Franzen, C. A., Foreman, K. E., Flanigan, R. C., Kuo, P. C., and Gupta, G. N. (2016). PLK-1 silencing in bladder cancer by siRNA delivered with exosomes. Urology 91, 241.e241-e247. doi: 10.1016/j.urology.2016. 01.028

Ha, D., Yang, N., and Nadithe, V. (2016). Exosomes as therapeutic drug carriers and delivery vehicles across biological membranes: current perspectives and future challenges. Acta Pharm. Sin. B 6, 287-296. doi: 10.1016/j.apsb.2016.02.001

Hadla, M., Palazzolo, S., Corona, G., Caligiuri, I., Canzonieri, V., Toffoli, G., et al. (2016). Exosomes increase the therapeutic index of doxorubicin in breast and ovarian cancer mouse models. Nanomedicine 11, 2431-2441. doi: 10.2217/nnm-2016-0154

Hall, J., Prabhakar, S., Balaj, L., Lai, C. P., Cerione, R. A., and Breakefield, X. O. (2016). Delivery of therapeutic proteins via extracellular vesicles: review and potential treatments for Parkinson's Disease, Glioma, and Schwannoma. Cell. Mol. Neurobiol. 36, 417-427. doi: 10.1007/s10571-015-0309-0

Hermans, I. F., Ritchie, D. S., Yang, J., Roberts, J. M., and Ronchese, F. (2000). CD8+ T cell-dependent elimination of dendritic cells in vivo limits the induction of antitumor immunity. J. Immunol. 164, 3095-3101. doi: 10.4049/jimmunol.164.6.3095

Hood, J. L. (2016). Post isolation modification of exosomes for nanomedicine applications. Nanomedicine 11, 1745-1756. doi: 10.2217/nnm-2016-0102

Hood, J. L., Scott, M. J., and Wickline, S. A. (2014). Maximizing exosome colloidal stability following electroporation. Anal. Biochem. 448, 41-49. doi: 10.1016/j.ab.2013.12.001

Hornick, N. I., Doron, B., Abdelhamed, S., Huan, J., Harrington, C. A., Shen, R., et al. (2016). AML suppresses hematopoiesis by releasing exosomes that contain microRNAs targeting c-MYB. Sci. Signal. 9, ra88. doi: 10.1126/scisignal.aaf2797

Hoshino, A., Costa-Silva, B., Shen, T. L., Rodrigues, G., Hashimoto, A., Tesic Mark, M., et al. (2015). Tumour exosome integrins determine organotropic metastasis. Nature 527, 329-335. doi: 10.1038/nature15756

Hu, Y., Yan, C., Mu, L., Huang, K., Li, X., Tao, D., et al. (2015). Fibroblast-derived exosomes contribute to chemoresistance through priming cancer stem cells in colorectal cancer. PLoS ONE 10:e0125625. doi: 10.1371/journal.pone.0125625

Huang, R., and Rofstad, E. K. (2016). Cancer stem cells (CSCs), cervical CSCs and targeted therapies. Oncotarget. doi: 10.18632/oncotarget.10169. [Epub ahead of print].

Hung, M. E., and Leonard, J. N. (2015). Stabilization of exosome-targeting peptides via engineered glycosylation. J. Biol. Chem. 290, 8166-8172. doi: $10.1074 /$ jbc.M114.621383

Hwang, I. (2013). Cell-cell communication via extracellular membrane vesicles and its role in the immune response. Mol. Cells 36, 105-111. doi: 10.1007/s10059013-0154-2

Jang, S. C., Kim, O. Y., Yoon, C. M., Choi, D. S., Roh, T. Y., Park, J., et al. (2013). Bioinspired exosome-mimetic nanovesicles for targeted delivery of chemotherapeutics to malignant tumors. ACS Nano 7, 7698-7710. doi: $10.1021 / \mathrm{nn} 402232 \mathrm{~g}$

Ji, R., Zhang, B., Zhang, X., Xue, J., Yuan, X., Yan, Y., et al. (2015). Exosomes derived from human mesenchymal stem cells confer drug resistance in gastric cancer. Cell Cycle 14, 2473-2483. doi: 10.1080/15384101.2015.1005530

Katakowski, M., Buller, B., Zheng, X., Lu, Y., Rogers, T., Osobamiro, O., et al. (2013). Exosomes from marrow stromal cells expressing miR-146b inhibit glioma growth. Cancer Lett. 335, 201-204. doi: 10.1016/j.canlet.2013.02.019

Kawikova, I., and Askenase, P. W. (2015). Diagnostic and therapeutic potentials of exosomes in CNS diseases. Brain Res. 1617, 63-71. doi: 10.1016/j.brainres.2014.09.070

Kharaziha, P., Ceder, S., Li, Q., and Panaretakis, T. (2012). Tumor cell-derived exosomes: a message in a bottle. Biochim. Biophys. Acta 1826, 103-111. doi: 10.1016/j.bbcan.2012.03.006

Kim, M. S., Haney, M. J., Zhao, Y., Mahajan, V., Deygen, I., Klyachko, N. L., et al. (2016). Development of exosome-encapsulated paclitaxel to overcome MDR in cancer cells. Nanomedicine 12, 655-664. doi: 10.1016/j.nano.2015.10.012

Klumperman, J., and Raposo, G. (2014). The complex ultrastructure of the endolysosomal system. Cold Spring Harb. Perspect. Biol. 6:a016857. doi: 10.1101/cshperspect.a016857

Kooijmans, S. A., Aleza, C. G., Roffler, S. R., van Solinge, W. W., Vader, P., and Schiffelers, R. M. (2016). Display of GPI-anchored anti-EGFR nanobodies on extracellular vesicles promotes tumour cell targeting. J. Extracell. Vesicles 5:31053. doi: 10.3402/jev.v5.31053

Kooijmans, S. A., Stremersch, S., Braeckmans, K., de Smedt, S. C., Hendrix, A., Wood, M. J., et al. (2013). Electroporation-induced siRNA precipitation obscures the efficiency of siRNA loading into extracellular vesicles. J. Control. Release 172, 229-238. doi: 10.1016/j.jconrel.2013. 08.014

Kudela, P., Koller, V. J., Mayr, U. B., Nepp, J., Lubitz, W., and BarisaniAsenbauer, T. (2011). Bacterial Ghosts as antigen and drug delivery system for ocular surface diseases: effective internalization of Bacterial Ghosts by human conjunctival epithelial cells. J. Biotechnol. 153, 167-175. doi: 10.1016/j.jbiotec.2011.03.022

Kudela, P., Paukner, S., Mayr, U. B., Cholujova, D., Kohl, G., Schwarczova, Z., et al. (2008). Effective gene transfer to melanoma cells using bacterial ghosts. Cancer Lett. 262, 54-63. doi: 10.1016/j.canlet.2007.11.031 
Kudela, P., Paukner, S., Mayr, U. B., Cholujova, D., Schwarczova, Z., Sedlak, J., et al. (2005). Bacterial ghosts as novel efficient targeting vehicles for DNA delivery to the human monocyte-derived dendritic cells. J. Immunother. 28, 136-143. doi: 10.1097/01.cji.0000154246.89630.6f

Lai, R. C., Tan, S. S., Teh, B. J., Sze, S. K., Arslan, F., de Kleijn, D. P., et al. (2012). Proteolytic potential of the MSC exosome proteome: implications for an exosome-mediated delivery of therapeutic proteasome. Int. J. Proteomics 2012:971907. doi: 10.1155/2012/971907

Li, X., Tsibouklis, J., Weng, T., Zhang, B., Yin, G., Feng, G., et al. (2016). Nano carriers for drug transport across the blood-brain barrier. J. Drug Target 11, 1-12. doi: 10.1080/1061186X.2016.1184272

Liu, L., Chang, S., Sun, J., Zhu, S., Yin, M., Zhu, Y., et al. (2015). Ultrasoundmediated destruction of paclitaxel and oxygen loaded lipid microbubbles for combination therapy in ovarian cancer xenografts. Cancer Lett. 361, 147-154. doi: 10.1016/j.canlet.2015.02.052

Lou, G., Song, X., Yang, F., Wu, S., Wang, J., Chen, Z., et al. (2015). Exosomes derived from miR-122-modified adipose tissue-derived MSCs increase chemosensitivity of hepatocellular carcinoma. J. Hematol. Oncol. 8, 122. doi: 10.1186/s13045-015-0220-7

Lu, B., Huang, X., Mo, J., and Zhao, W. (2016). Drug Delivery Using Nanoparticles for cancer stem-like cell targeting. Front. Pharmacol. 7:84. doi: 10.3389/fphar.2016.00084

Luketic, L., Delanghe, J., Sobol, P. T., Yang, P., Frotten, E., Mossman, K. L., et al. (2007). Antigen presentation by exosomes released from peptide-pulsed dendritic cells is not suppressed by the presence of active CTL. J. Immunol. 179, 5024-5032. doi: 10.4049/jimmunol.179.8.5024

Lunavat, T. R., Jang, S. C., Nilsson, L., Park, H. T., Repiska, G., Lässer, C., et al. (2016). RNAi delivery by exosome-mimetic nanovesiclesImplications for targeting c-Myc in cancer. Biomaterials 102, 231-238. doi: 10.1016/j.biomaterials.2016.06.024

Magnani, M., Rossi, L., Fraternale, A., Bianchi, M., Antonelli, A., Crinelli, R., et al. (2002). Erythrocyte-mediated delivery of drugs, peptides and modified oligonucleotides. Gene Ther. 9, 749-751. doi: 10.1038/sj.gt.3301758

Mahaweni, N. M., Kaijen-Lambers, M. E., Dekkers, J., Aerts, J. G., and Hegmans, J. P. (2013). Tumour-derived exosomes as antigen delivery carriers in dendritic cell-based immunotherapy for malignant mesothelioma. J Extracell Vesicles 2:22492. doi: 10.3402/jev.v2i0.22492

Malhotra, H., Sheokand, N., Kumar, S., Chauhan, A. S., Kumar, M., Jakhar, P., et al. (2016). Exosomes: tunable nano vehicles for macromolecular delivery of transferrin and lactoferrin to specific intracellular compartment. J. Biomed. Nanotechnol. 12, 1101-1114. doi: 10.1166/jbn.2016.2229

Mao, L., Li, J., Chen, W. X., Cai, Y. Q., Yu, D. D., Zhong, S. L., et al. (2016). Exosomes decrease sensitivity of breast cancer cells to adriamycin by delivering microRNAs. Tumour Biol. 37, 5247-5256. doi: 10.1007/s13277-015-4402-2

Marhaba, R., Klingbeil, P., Nuebel, T., Nazarenko, I., Buechler, M. W., and Zoeller, M. (2008). CD44 and EpCAM: cancer-initiating cell markers. Curr. Mol. Med. 8, 784-804. doi: 10.2174/156652408786733667

Mayr, U. B., Haller, C., Haidinger, W., Atrasheuskaya, A., Bukin, E., Lubitz, W., et al. (2005). Bacterial ghosts as an oral vaccine: a single dose of Escherichia coli O157:H7 bacterial ghosts protects mice against lethal challenge. Infect. Immun. 73, 4810-4817. doi: 10.1128/IAI.73.8.4810-4817.2005

Melo, S. A., Sugimoto, H., O'Connell, J. T., Kato, N., Villanueva, A., Vidal, A., et al. (2014). Cancer exosomes perform cell-independent microRNA biogenesis and promote tumorigenesis. Cancer Cell 26, 707-721. doi: 10.1016/j.ccell.2014.09.005

Momen-Heravi, F., Bala, S., Bukong, T., and Szabo, G. (2014). Exosomemediated delivery of functionally active miRNA-155 inhibitor to macrophages. Nanomedicine 10, 1517-1527. doi: 10.1016/j.nano.2014.03.014

Morse, M. A., Garst, J., Osada, T., Khan, S., Hobeika, A., Clay, T. M., et al. (2005). A phase I study of dexosome immunotherapy in patients with advanced non-small cell lung cancer. J. Transl. Med. 3:9. doi: 10.1186/1479-5876-3-9

Munagala, R., Aqil, F., Jeyabalan, J., and Gupta, R. C. (2016). Bovine milk-derived exosomes for drug delivery. Cancer Lett. 371, 48-61. doi: 10.1016/j.canlet. 2015.10.020

Munoz, J. L., Bliss, S. A., Greco, S. J., Ramkissoon, S. H., Ligon, K. L., and Rameshwar, P. (2013). Delivery of functional anti-miR-9 by mesenchymal stem cell-derived exosomes to glioblastoma multiforme cells conferred chemosensitivity. Mol. Ther. Nucleic Acids 2, e126. doi: 10.1038/mtna.2013.60
Muzykantov, V. R. (2010). Drug delivery by red blood cells: vascular carriers designed by mother nature. Expert Opin. Drug Deliv. 7, 403-427. doi: $10.1517 / 17425241003610633$

Nakase, I., and Futaki, S. (2015). Combined treatment with a pH-sensitive fusogenic peptide and cationic lipids achieves enhanced cytosolic delivery of exosomes. Sci. Rep. 5:10112. doi: 10.1038/srep10112

O’Brien, K., Lowry, M. C., Corcoran, C., Martinez, V. G., Daly, M., Rani, S., et al. (2015). miR-134 in extracellular vesicles reduces triple-negative breast cancer aggression and increases drug sensitivity. Oncotarget 6, 32774-32789. doi: 10.18632/oncotarget.5192

Ohno, S., Takanashi, M., Sudo, K., Ueda, S., Ishikawa, A., Matsuyama, N., et al. (2013). Systemically injected exosomes targeted to EGFR deliver antitumor microRNA to breast cancer cells. Mol. Ther. 21, 185-191. doi: 10.1038/ mt.2012.180

Pascucci, L., Coccè, V., Bonomi, A., Ami, D., Ceccarelli, P., Ciusani, E., et al. (2014). Paclitaxel is incorporated by mesenchymal stromal cells and released in exosomes that inhibit in vitro tumor growth: a new approach for drug delivery. J. Control. Release 192, 262-270. doi: 10.1016/j.jconrel.2014.07.042

Paukner, S., Kudela, P., Kohl, G., Schlapp, T., Friedrichs, S., and Lubitz, W. (2005). DNA-loaded bacterial ghosts efficiently mediate reporter gene transfer and expression in macrophages. Mol. Ther. 11, 215-223. doi: 10.1016/j.ymthe.2004.09.024

Piktel, E., Niemirowicz, K., Watek, M., Wollny, T., Deptula, P., and Bucki, R. (2016). Recent insights in nanotechnology-based drugs and formulations designed for effective anti-cancer therapy. J. Nanobiotechnology 14:39. doi: 10.1186/s12951-016-0193-x

Pitt, J. M., André, F., Amigorena, S., Soria, J. C., Eggermont, A., Kroemer, G., et al. (2016). Dendritic cell-derived exosomes for cancer therapy. J. Clin. Invest. 126, 1224-1232. doi: 10.1172/JCI81137

Qi, H., Liu, C., Long, L., Ren, Y., Zhang, S., Chang, X., et al. (2016). Blood exosomes endowed with magnetic and targeting properties for cancer therapy. ACS Nano 10, 3323-3333. doi: 10.1021/acsnano.5b06939

Raimondo, F., Morosi, L., Chinello, C., Magni, F., and Pitto, M. (2011). Advances in membranous vesicle and exosome proteomics improving biological understanding and biomarker discovery. Proteomics 11, 709-720. doi: 10.1002/pmic.201000422

Rana, S., Yue, S., Stadel, D., and Zöller, M. (2012). Toward tailored exosomes: the exosomal tetraspanin web contributes to target cell selection. Int. J. Biochem. Cell Biol. 44, 1574-1584. doi: 10.1016/j.biocel.2012.06.018

Raposo, G., and Stoorvogel, W. (2013). Extracellular vesicles: exosomes, microvesicles, and friends. J. Cell Biol. 200, 373-383. doi: 10.1083/jcb.201 211138

Rinkenbaugh, A. L., and Baldwin, A. S. (2016). The NF- $\kappa$ B pathway and cancer stem cells. Cells 5:16. doi: 10.3390/cells5020016

Roccaro, A. M., Sacco, A., Maiso, P., Azab, A. K., Tai, Y. T., Reagan, M., et al. (2013). BM mesenchymal stromal cell-derived exosomes facilitate multiple myeloma progression. J. Clin. Invest. 123, 1542-1555. doi: 10.1172/JCI66517

Saari, H., Lázaro-Ibáñez, E., Viitala, T., Vuorimaa-Laukkanen, E., Siljander, P., and Yliperttula, M. (2015). Microvesicle- and exosome-mediated drug delivery enhances the cytotoxicity of Paclitaxel in autologous prostate cancer cells. J Control Release 220(Pt B), 727-737. doi: 10.1016/j.jconrel.2015.09.031

Saha, S., Adhikary, A., Bhattacharyya, P., Das, T., and Sa, G. (2012). Death by design: where curcumin sensitizes drug-resistant tumours. Anticancer Res. 32, 2567-2584.

Sales, K. M., Winslet, M. C., and Seifalian, A. M. (2007). Stem cells and cancer: an overview. Stem Cell Rev. 3, 249-255. doi: 10.1007/s12015-007-9002-0

Sato, Y. T., Umezaki, K., Sawada, S., Mukai, S. A., Sasaki, Y., Harada, N., et al. (2016). Engineering hybrid exosomes by membrane fusion with liposomes. Sci. Rep. 6:21933. doi: 10.1038/srep21933

Schorey, J. S., and Bhatnagar, S. (2008). Exosome function: from tumor immunology to pathogen biology. Traffic 9, 871-881. doi: 10.1111/j.16000854.2008.00734.x

Seow, Y., and Wood, M. J. (2009). Biological gene delivery vehicles: beyond viral vectors. Mol. Ther. 17, 767-777. doi: 10.1038/mt.2009.41

Shimbo, K., Miyaki, S., Ishitobi, H., Kato, Y., Kubo, T., Shimose, S., et al. (2014). Exosome-formed synthetic microRNA-143 is transferred to osteosarcoma cells and inhibits their migration. Biochem. Biophys. Res. Commun. 445, 381-387. doi: 10.1016/j.bbrc.2014.02.007 
Shtam, T. A., Kovalev, R. A., Varfolomeeva, E. Y., Makarov, E. M., Kil, Y. V., and Filatov, M. V. (2013). Exosomes are natural carriers of exogenous siRNA to human cells in vitro. Cell Commun. Signal. 11:88. doi: $10.1186 / 1478-811 \mathrm{X}-11-88$

Smyth, T. J., Redzic, J. S., Graner, M. W., and Anchordoquy, T. J. (2014). Examination of the specificity of tumor cell derived exosomes with tumor cells in vitro. Biochim. Biophys. Acta 1838, 2954-2965. doi: 10.1016/j.bbamem.2014.07.026

Soltani, F., Parhiz, H., Mokhtarzadeh, A., and Ramezani, M. (2015). Synthetic and biological vesicular nano-carriers designed for gene delivery. Curr. Pharm. Des. 21, 6214-6235. doi: 10.2174/1381612821666151027 153410

Sotiropoulou, P. A., Christodoulou, M. S., Silvani, A., Herold-Mende, C., and Passarella, D. (2014). Chemical approaches to targeting drug resistance in cancer stem cells. Drug Discov. Today 19, 1547-1562. doi: 10.1016/j.drudis. 2014.05.002

Srivastava, A., Babu, A., Filant, J., Moxley, K. M., Ruskin, R., Dhanasekaran, D., et al. (2016). Exploitation of exosomes as nanocarriers for gene-, chemo-, and immune-therapy of cancer. J. Biomed. Nanotechnol. 12, 1159-1173. doi: $10.1166 /$ jbn.2016.2205

Stickney, Z., Losacco, J., McDevitt, S., Zhang, Z., and Lu, B. (2016). Development of exosome surface display technology in living human cells. Biochem. Biophys. Res. Commun. 472, 53-59. doi: 10.1016/j.bbrc.2016. 02.058

Sun, D., Zhuang, X., Xiang, X., Liu, Y., Zhang, S., Liu, C., et al. (2010). A novel nanoparticle drug delivery system: the anti-inflammatory activity of curcumin is enhanced when encapsulated in exosomes. Mol. Ther. 18, 1606-1614. doi: $10.1038 / \mathrm{mt} .2010 .105$

Tang, M. K., and Wong, A. S. (2015). Exosomes: emerging biomarkers and targets for ovarian cancer. Cancer Lett. 367, 26-33. doi: 10.1016/j.canlet.2015.07.014

Tang, X. J., Sun, X. Y., Huang, K. M., Zhang, L., Yang, Z. S., Zou, D. D., et al. (2015). Therapeutic potential of CAR-T cell-derived exosomes: a cell-free modality for targeted cancer therapy. Oncotarget 6, 44179-44190. doi: 10.18632/oncotarget.6175

Tauro, B. J., Greening, D. W., Mathias, R. A., Ji, H., Mathivanan, S., Scott, A. M., et al. (2012). Comparison of ultracentrifugation, density gradient separation, and immunoaffinity capture methods for isolating human colon cancer cell line LIM1863-derived exosomes. Methods 56, 293-304. doi: 10.1016/j.ymeth.2012.01.002

Taylor, D. D., and Gercel-Taylor, C. (2008). MicroRNA signatures of tumor-derived exosomes as diagnostic biomarkers of ovarian cancer. Gynecol. Oncol. 110, 13-21. doi: 10.1016/j.ygyno.2008.04.033

Théry, C., Zitvogel, L., and Amigorena, S. (2002). Exosomes: composition, biogenesis and function. Nat. Rev. Immunol. 2, 569-579. doi: 10.1038/nri855

Tian, X., Zhu, M., and Nie, G. (2013). How can nanotechnology help membrane vesicle-based cancer immunotherapy development? Hum. Vaccin. Immunother. 9, 222-225. doi: 10.4161/hv.22130

Tian, Y., Li, S., Song, J., Ji, T., Zhu, M., Anderson, G. J., et al. (2014). A doxorubicin delivery platform using engineered natural membrane vesicle exosomes for targeted tumor therapy. Biomaterials 35, 2383-2390. doi: 10.1016/j.biomaterials.2013.11.083

Toffoli, G., Hadla, M., Corona, G., Caligiuri, I., Palazzolo, S., Semeraro, S., et al. (2015). Exosomal doxorubicin reduces the cardiac toxicity of doxorubicin. Nanomedicine 10, 2963-2971. doi: 10.2217/nnm.15.118

Umezu, T., Tadokoro, H., Azuma, K., Yoshizawa, S., Ohyashiki, K., and Ohyashiki, J. H. (2014). Exosomal miR-135b shed from hypoxic multiple myeloma cells enhances angiogenesis by targeting factor-inhibiting HIF-1. Blood 124, 3748-3757. doi: 10.1182/blood-2014-05-576116
Vader, P., Mol, E. A., Pasterkamp, G., and Schiffelers, R. M. (2016). Extracellular vesicles for drug delivery. Adv. Drug Deliv. Rev. 106(Part A), 148-156. doi: 10.1016/j.addr.2016.02.006

van der Meel, R., Fens, M. H., Vader, P., van Solinge, W. W., Eniola-Adefeso, O., and Schiffelers, R. M. (2014). Extracellular vesicles as drug delivery systems: lessons from the liposome field. J. Control. Release 195, 72-85. doi: 10.1016/j.jconrel.2014.07.049

Viaud, S., Ploix, S., Lapierre, V., Théry, C., Commere, P. H., Tramalloni, D., et al. (2011). Updated technology to produce highly immunogenic dendritic cell-derived exosomes of clinical grade: a critical role of interferon-gamma. J. Immunother. 34, 65-75. doi: 10.1097/CJI.0b013e3181fe535b

Wahlgren, J., De, L. K. T., Brisslert, M., Vaziri Sani, F., Telemo, E., Sunnerhagen, P., et al. (2012). Plasma exosomes can deliver exogenous short interfering RNA to monocytes and lymphocytes. Nucleic Acids Res. 40, e130. doi: $10.1093 /$ nar/gks463

Wang, J., De Veirman, K., De Beule, N., Maes, K., De Bruyne, E., Van Valckenborgh, E., et al. (2015). The bone marrow microenvironment enhances multiple myeloma progression by exosome-mediated activation of myeloid-derived suppressor cells. Oncotarget 6, 43992-44004. doi: 10.18632/ oncotarget.6083

Wang, J., De Veirman, K., Faict, S., Frassanito, M. A., Ribatti, D., Vacca, A., et al. (2016a). Multiple myeloma exosomes establish a favourable bone marrow microenvironment with enhanced angiogenesis and immunosuppression. J. Pathol. 239, 162-173. doi: 10.1002/path.4712

Wang, J., Faict, S., Maes, K., De Bruyne, E., Van Valckenborgh, E., Schots, R., et al. (2016b). Extracellular vesicle cross-talk in the bone marrow microenvironment: implications in multiple myeloma. Oncotarget 7, 38927-38945. doi: 10.18632/oncotarget.7792

Wang, J., Hendrix, A., Hernot, S., Lemaire, M., De Bruyne, E., Van Valckenborgh, E., et al. (2014). Bone marrow stromal cell-derived exosomes as communicators in drug resistance in multiple myeloma cells. Blood 124, 555-566. doi: 10.1182/blood-2014-03-562439

Watson, D. C., Bayik, D., Srivatsan, A., Bergamaschi, C., Valentin, A., Niu, G., et al. (2016). Efficient production and enhanced tumor delivery of engineered extracellular vesicles. Biomaterials 105, 195-205. doi: 10.1016/j.biomaterials.2016.07.003

Yang, Z. F., Ho, D. W., Ng, M. N., Lau, C. K., Yu, W. C., Ngai, P., et al. (2008). Significance of CD90+ cancer stem cells in human liver cancer. Cancer Cell 13, 153-166. doi: 10.1016/j.ccr.2008.01.013

Yousefpour, P., and Chilkoti, A. (2014). Co-opting biology to deliver drugs. Biotechnol. Bioeng. 111, 1699-1716. doi: 10.1002/bit.25307.

Yu, S., Cao, H., Shen, B., and Feng, J. (2015). Tumor-derived exosomes in cancer progression and treatment failure. Oncotarget 6, 37151-37168. doi: 10.18632/oncotarget.6022

Zhang, L., Zhang, S., Yao, J., Lowery, F. J., Zhang, Q., Huang, W. C., et al. (2015). Microenvironment-induced PTEN loss by exosomal microRNA primes brain metastasis outgrowth. Nature 527, 100-104. doi: 10.1038/nature15376

Conflict of Interest Statement: The authors declare that the research was conducted in the absence of any commercial or financial relationships that could be construed as a potential conflict of interest.

Copyright (c) 2017 Wang, Zheng and Zhao. This is an open-access article distributed under the terms of the Creative Commons Attribution License (CC BY). The use, distribution or reproduction in other forums is permitted, provided the original author(s) or licensor are credited and that the original publication in this journal is cited, in accordance with accepted academic practice. No use, distribution or reproduction is permitted which does not comply with these terms. 